U1) norden

Strategy for International Branding of the Nordic Region

2015-2018

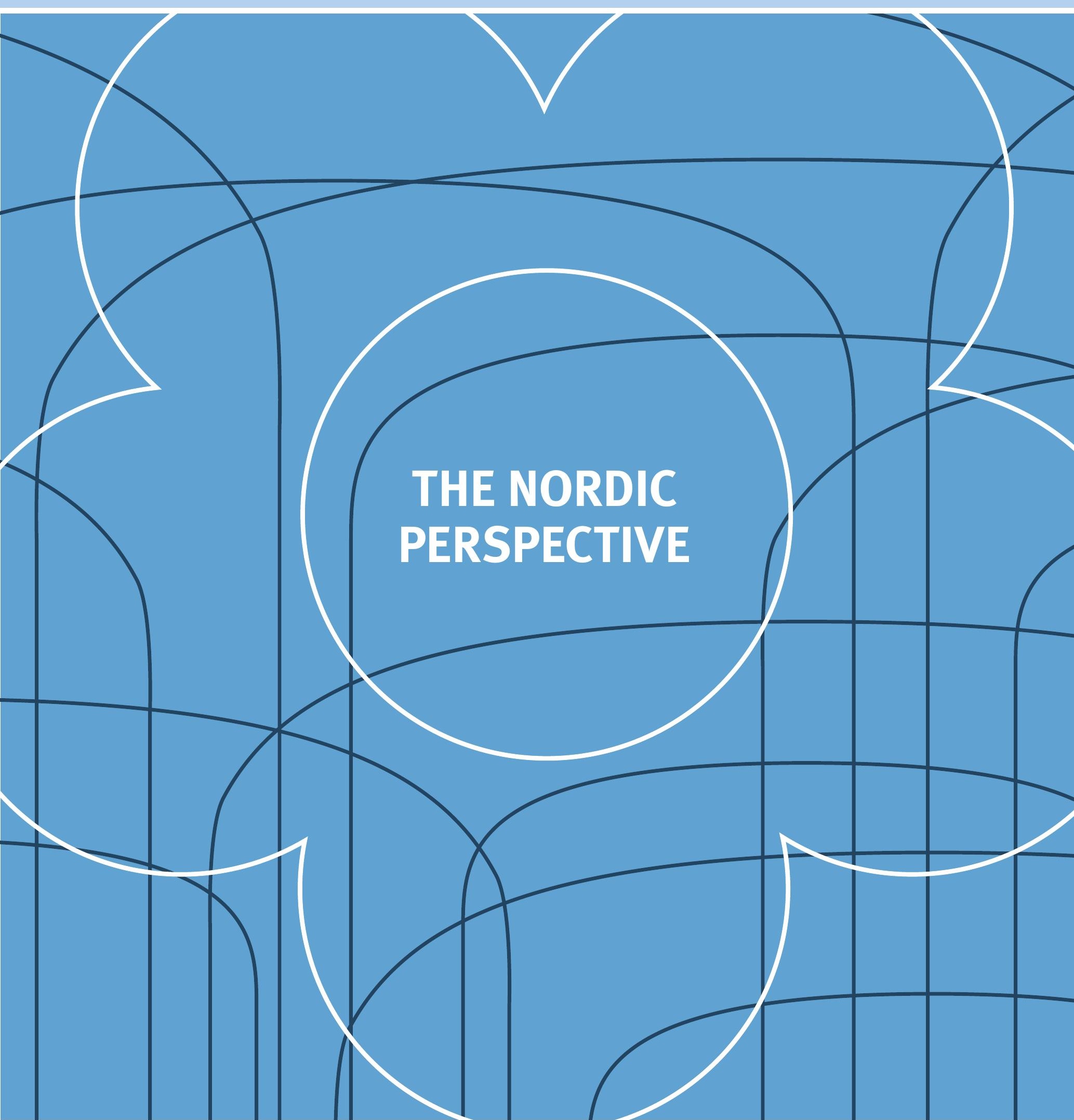




\section{Strategy for International Branding of the Nordic Region 2015-2018}

ISBN 978-92-893-3932-2 (PRINT)

ISBN 978-92-893-3933-9 (PDF)

http://dx.doi.org/10.6027/ANP2015-708

ANP 2015:708

(C) Nordic Council of Ministers 2015

Layout: Erling Lynder

Print: Rosendahls-Schultz Grafisk

Copies: 400

Printed in Denmark

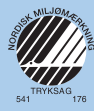

www.norden.org/en/publications

Nordic Council of Ministers

Ved Stranden 18

DK-1061 Copenhagen $\mathrm{K}$

Phone (+45) 33960200

\section{Nordic co-operation}

Nordic co-operation is one of the world's most extensive forms of regional collaboration, involving Denmark, Finland, Iceland, Norway, Sweden, and the Faroe Islands, Greenland, and Åland.

Nordic co-operation has firm traditions in politics, the economy, and culture. It plays an important role in European and international collaboration, and aims at creating a strong Nordic community in a strong Europe.

Nordic co-operation seeks to safeguard Nordic and regional interests and principles in the global community. Common Nordic values help the region solidify its position as one of the world's most innovative and competitive. 


\section{Strategy for International Branding of the Nordic Region}

2015-2018

Foreword 5

1. Background 7

$\begin{array}{ll}\text { 1.1 The Prime Ministers } & 7\end{array}$

1.2 Vision of the Nordic Ministers for Co-operation 7

1.3 Nordic Cool

1.4 Pilot study $\quad 8$

2. Strategy for International Branding of the Nordic Region 9

2.1 Aim of the strategy 9

2.2 Common platform $\quad 10$

2.3 Illustration: The Nordic Perspective 11

3. The Nordic Story 13

4. Use of the strategy 16

4.1 Strategic areas for branding $\quad 16$

4.2 Prioritised geographical areas $\quad 19$

5. Target groups 20

6. Objectives 21

7. Success criteria for projects and activities 22

8. Budget 23

9. Schedule and implementation 24

9.1 Implementation plan $\quad 24$

10. Practical tools 25 


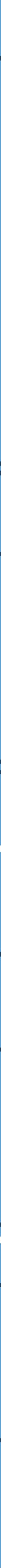




\section{Foreword}

The Nordic region is appealing. For some time, characteristically Nordic cuisine, design, films, music and literature have been bringing the Nordic region international recognition. The successes, which come from all the Nordic countries, often share a distinctly Nordic element - a Nordic trademark.

However, the Nordic region first started to distinguish itself internationally in the aftermath of the financial crisis. The Nordic governance and welfare model once again showed it was capable of renewing itself. Countries all over the world then began to discuss whether our model could serve as a possible buffering and stabilising factor in an increasingly uncertain global economy.

We in the Nordic region are also facing a number of serious challenges. We are far from perfect, and it is perhaps this imperfection that makes us fascinating.

At the same time, we are always at the top of international rankings regarding openness, trust, equality, environment and happiness. These are the values we want to share with the rest of the world, along with our pragmatic politics, dark thrillers, and the strong role of women.

Consequently, on several occasions, the Nordic prime ministers have expressed a wish for the Nordic region to raise its profile internationally. For many years, the Nordic countries have each been carrying out successful branding activities internationally, but, on the basis of the prime ministers' view that together we are stronger, we now want to brand the Nordic countries under a single and unified concept.

By working together, we not only boost our political and economic impact; we can also contribute to development in the world, while the meeting with the outside world also enables us to develop ourselves.

The objective is not to convey a homogeneous picture of the countries in the Nordic region, nor to give an impression that all Nordic citizens, organisations and governments think and behave in the same way. Instead of emphasising the distinctive features of each country, our aim is to promote what we have in common - our Nordic perspective, our values, and a culture that has grown out of a common history. 
In systematising and increasing the visibility of the Nordic region internationally, this new branding strategy marks the start of new and historic co-operation between the Nordic countries.

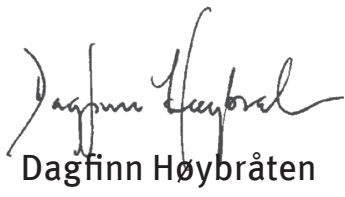

Secretary General of

the Nordic Council of Ministers

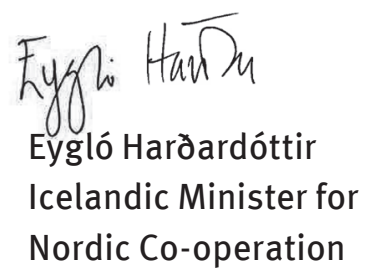




\section{Background}

Commissioned by the Nordic Ministers for Co-operation, the Secretariat to the Nordic Council of Ministers has drawn up a strategy for international branding of the Nordic region. This has been done after broad anchoring with external parties, in the public and private sectors of the Nordic countries, and internally in the Nordic co-operation networks. The Secretariat will administer and coordinate the work relating to the strategy, in dialogue and collaboration with the countries.

The strategy sets up some strategic guidelines for international branding of the Nordic region and its stakeholders, and is also an offer to all players outside the official Nordic co-operation.

\subsection{The Prime Ministers}

At their meeting in Mývatn on 27th May 2014, the Nordic Prime Ministers expressed a strong hope for increased Nordic coordination and visibility. One of their priorities was the work on regional branding, with the aim of strengthening the competitiveness of the Nordic countries and improving opportunities for the Nordic region to exert influence internationally.

\subsection{Vision of the Nordic Ministers for Co-operation}

The vision declaration of the Ministers for Co-operation, Together We Are Stronger, ${ }^{1}$ identifies an innovative, visible and outward-looking Nordic region as important characteristics for the co-operation. The vision also underlines how the joint Nordic experiences can be very significant for others in a world in which the importance of regional collaboration is increasing. The vision is based on the following four pillars:

- Freedom of movement.

- Innovation.

- Visibility.

- International engagement.

\subsection{Nordic Cool}

With the successful major initiative, Nordic Cool 2013, in Washington D.C., USA, as the leading example, interest grew in implementing more branding activities involving a large number of partners throughout the Nordic region. Parallel with the distinctly branding-oriented cultural events in the Kennedy Center, a variety of activities were arranged with the aim of showing what the Nordic region can contribute, both innovatively and politically. The event was also a success in the media, thereby increasing the impact. Another lesson learned was that implementing

1 The Nordic Region Together We Are Stronger, Nordic Ministers for Cooperation vision for Nordic co-operation (2014). 
large, joint initiatives takes a lot of time and resources, ${ }^{2}$ and that a strategic approach is crucial.

\subsection{Pilot study}

In agreement with the vision of the Ministers for Co-operation, a comprehensive pilot study carried out in winter 2013/2014 recommended that the Nordic region form a branding team, comprising Nordic and international representatives of both public and private sectors. The pilot study showed broad support for a strategy. ${ }^{3}$ Such a strategy could:

- ensure consistent branding of the Nordic region

- highlight and clarify the common messages.

More arguments from the pilot study, and the subsequent work, about why a strategy should be drawn up and why now:

- The outside world defines the Nordic region as a unit, and the further away geographically the more this is the case.

- The outside world has shown increasing interest in the Nordic region and the Nordic Model. The region's standing has risen because of the way the financial crisis has been tackled since 2008 , and because of other solutions to the welfare issue, but also because of the successes in the cultural, creative and innovative arenas.

- In both the public and private sectors, there is great Nordic interest in joint branding activities that generate added value.

- The Nordic countries top international indices that measure openness, tolerance and trust. International media virtually always point this out in a Nordic context.

- In order to capitalise on the power of the Nordic brand, spread the message, and reach the desired position, we should take control of the brand, actively working with it, and consistently communicating a coherent and clear picture. 


\section{Strategy for International Branding of the Nordic Region}

The outside world essentially defines the Nordic region as a unit. ${ }^{4}$ The image is positive, largely because we in the Nordic region seem to have found solutions to economic and political challenges that both we and others are grappling with. The Nordic Model has become a concept. Every Nordic country has built its own model, parallel with extensive and permanent co-operation within the Nordic region.

If the Nordic region is to continue to develop strongly, we are dependent on what is happening around us and on other countries being interested in us. It is in our interest to contribute to our own future and that of others by sharing ideas, expertise, experiences, services and goods.

Competition for a place on the international arena is tough, and small countries like ours can work together to generate greater visibility and influence. Coordinated branding activities in a joint initiative can generate synergies in the public and/or private sectors in each country.

The strategy sets up some strategic guidelines for international branding of the Nordic region and its stakeholders. This is a first step in a long-term initiative to systematise and ensure consistent branding of the Nordic region, and to produce an offer that supports the ability to work together towards a common goal when this generates added value for each player. There are other reasons than branding for acting internationally, such as diplomacy and sharing experiences, but this strategy does not apply to these.

The strategy applies for the period 2015-2018, after which it will be the subject of a detailed evaluation. Proposed changes will be decided by the Nordic Ministers for Co-operation (MR-SAM). Any minor updates will be implemented once a year and will be decided by the Nordic Committee for Co-operation (NSK).

\subsection{Aim of the strategy}

The competitiveness and international influence of the Nordic region and the Nordic countries will be strengthened through coordinated branding activities in a joint initiative.

The positive international attention regarding the Nordic region and countries will be utilised and strengthened by increasingly using the Nordic region as a concept, not least in markets where awareness of the region is greater than awareness of each individual country. More coordinated activities will also strengthen existing relationships in the more 
immediate geographical vicinity. The strategy will simplify and improve the work on branding the Nordic region at international level. It will explain the purpose of branding, provide support, and refer to tangible tools that will be made available to all parties.

\subsection{Common platform}

Using the term "The Nordic Region" as a unified concept enables each country or player to refer to characteristics that do not apply specifically and individually to Sweden, Denmark, Norway, Finland, or Iceland, or Åland, the Faroe Islands or Greenland. For example, branding can emphasise being part of a strong region with a population of 26 million, and a large and diverse range of industries and culture, not to mention a varied and fascinating natural environment.

In this particular context, the Nordic region can be described as a brand, i.e. the overall image of associations, feelings, experiences and expectations aroused in the recipient. Nothing, neither a country nor a region, really controls its image, especially in today's transparent, fast-moving and increasingly digital communication landscape. The image is earned. For long-term and sustainable relations with other countries, the offer must be genuine. You have to be what you claim to be and want to be.

What binds the Nordic countries together is what creates sufficient strength to attract the interest of the outside world. After years of close and successful co-operation, it is possible that we in the Nordic region take our common areas of strength for granted. Nevertheless, in the strategy for branding the Nordic region, which steers how we communicate what we are and what we want, it is important to express the common advantages we feel we have in relation to the outside world.

5 The Global Competitiveness Report 2014-2015, World Economic Forum (2014).

6 Quality of Life Index, The Economist Intelligence Unit (2014).

7 The Global Gender Gap Report 2013, World Economic Forum (2013).

8 A Pilot Study on the Need for a Joint Nordic Branding Strategy, Nordic Council of Ministers Communications Department and Happy Forsman \& Bodenfors (2014).
What is the explanation for the high rankings of the Nordic countries in global surveys of competitiveness, ${ }^{5}$ quality of life ${ }^{6}$ and equality? ${ }^{7}$ And why is it that interest in Nordic creativity and culture is so great just now? The outside world is curious about the Nordic countries, and about how we have managed to develop and achieve strong results even in tough times. ${ }^{8}$ What are the underlying factors? What is it that we do?

In the illustration on the next page, we have compiled factors that were emphasised in the broad anchoring process ahead of this strategy. The illustration can also be seen as a check list of the perspectives we want to express in our communication and in our relations with the world around us. Individually, they are neither unique nor radical, but together they show a Nordic way of thinking that we call the Nordic Perspective. 


\subsection{Illustration: The Nordic Perspective}

\section{BACKGROUND FACTORS}

\section{GEOGRAPHY}

- Vast areas.

- Sparsely populated.

- Forests, mountains, fields.

- Surrounded by sea.

- Tough climate.

- Dark winters.

- Intensive light in summer.

\section{SOCIETY}

- Comprehensive social safety net and welfare services.

- Free education for all citizens.

- High and equal standard of living.

- Gender-equal level of employment.

- Strong civil society.

- High-tech and specialised industry.

- State allocates substantial resources to research and development.

\section{HISTORY}

- Long history of peace in the Nordic region (200 years).

- Tradition of popular movements.

- Long history of collaboration in the Nordic region:

- Labour market.

- Passport union.

- Coordinated solutions for social security.

- Small societies enabled flat hierarchies.

- Long tradition of industry, innovation and entrepreneurship.

\section{CULTURE}

- Natural environment features prominently in:

- literature

- art

- architecture.

- Nordic creativity has attracted attention:

- Nordic Noir.

- Nordic Cuisine.

- Nordic Design. 


\section{Strengths we want to express}

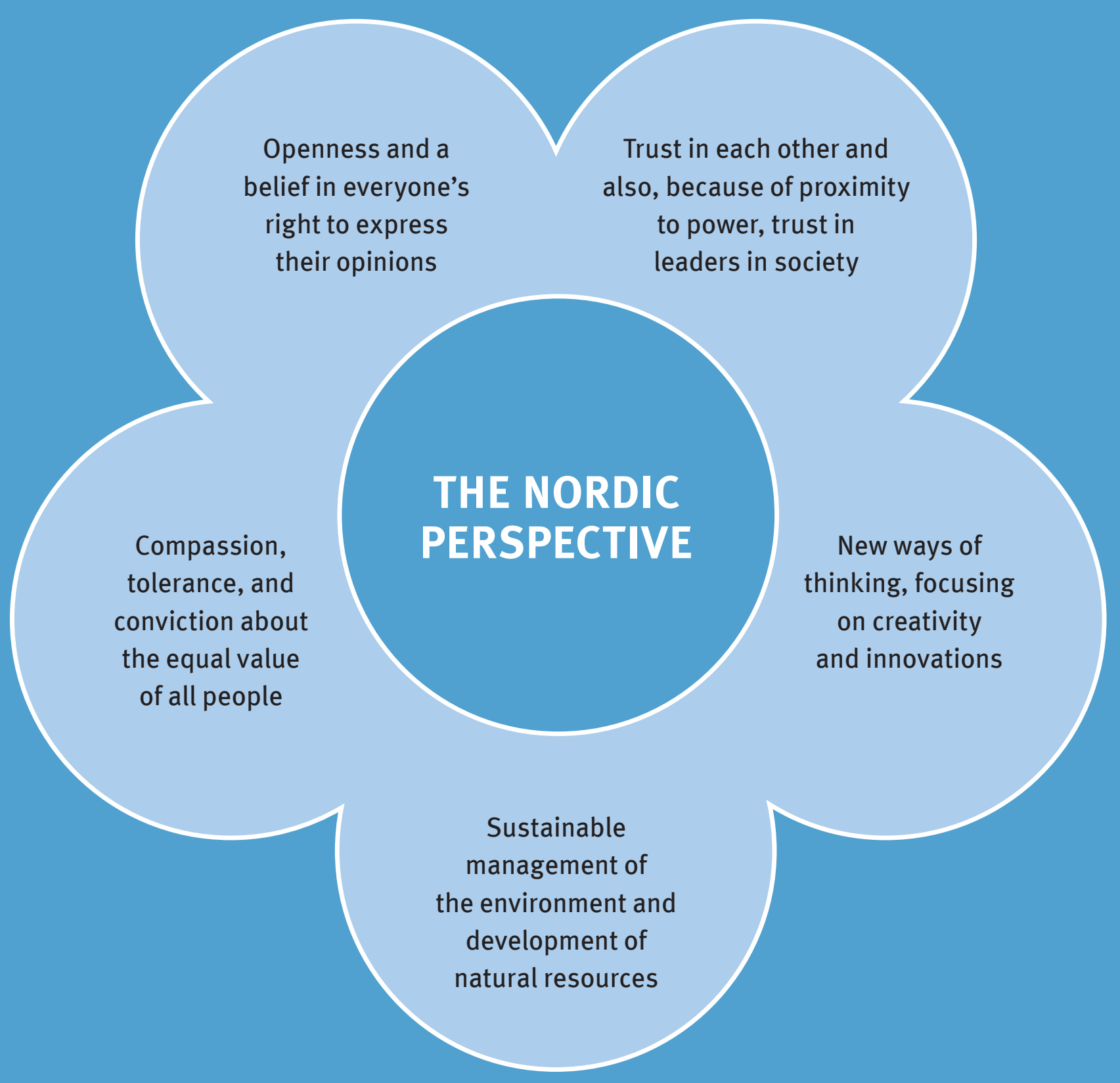




\section{The Nordic Story}

The illustration of the Nordic perspective, which describes a common platform of shared Nordic strengths in the form of characteristics and values, can also be presented as a story. This can inspire representatives of, and spokespersons for, the Nordic region in the work of communicating what we stand for, what we want, and what we can do in relation to the world around us.

The story, which is short and therefore simplified, can be developed and combined with other messages.

\section{The Nordic Perspective}

In the northern part of the Northern Hemisphere lives a relatively small group of people on large areas of land connected by an even larger area of water. This is a way to describe the five countries of the Nordic region - Sweden, Denmark, Norway, Finland and Iceland, and Greenland, the Faroe Islands and Åland - with a combined population of 26 million people. However, to complete the picture, it must be added that the countries have together developed into welfare societies positioned among the leading economies in the world.

The tough climate, with its long and dark winters but also the intensive light of the summer, and the riches of the seas, forests, mountains and fields, have created the special bond between Nordic people and nature. A distinct need for space with room to breathe - on the sea, in the mountains or in the forest - has influenced today's protective attitude to the environment and natural resources.

In the modern Nordic region, we seek sustainable environmental technology solutions, while the sustainability approach also affects the relationship to health and food. Anyone coming to the Nordic region to work, study or carry out research discovers the importance placed by business and society on the ability to lead a human and balanced life, with time for both career and social relationships. And we hope that anyone coming here as a tourist will gladly become an ambassador for Nordic nature and culture. 
9 Does the Nordic Model Need to Change? ETLA Research Institute of the Finnish Economy $\&$ Nordic Council of Ministers (2014)

10 The Nordic Way, World Economic Forum, Swedish Institute (2012).

11 The Nordic Countries - The next super model, the Economist (2013).

12 Does the Nordic Model Need to Change? ETLA Research Institute of the Finnish Economy $\&$ Nordic Council of Ministers (2014).
The relationship to nature, to the conditions imposed by the Nordic space, also features widely in literature, music, art, design and architecture. Art and creativity are really what are now helping to put the Nordic region on the world map, both the traditional Nordic and the one influenced by the meeting with the new, modern and increasingly multicultural Nordic region. Demand for what is sometimes called Nordic Noir in literature and films has never been greater.

Our common history is far from conflict-free, but today we can celebrate more than 200 years of peace between our countries. Give and take, finding pragmatic solutions that benefit all parties, is a trade mark, and we are proud that prominent people from the Nordic region are able to contribute in current mediation processes between opposing parties in conflicts. The Nordic countries aim to show engagement and presence in peacekeeping organisations, and we believe that aid in solidarity with vulnerable people creates a better world. In Norway, the Peace Prize in memory of Alfred Nobel is awarded every year.

An ability to constantly reform in order to meet new challenges is a characteristic of the Nordic Model. Changes in society as a whole, such as The Reformation and popular movements, including the workers' movement, came first in historical terms, but soon everyone was supporting the model. The Nordic Model is characterised today by a public sector that provides its citizens with welfare services and a social safety net. The labour market is highly regulated by collective agreements between labour market parties. Combined with healthy state finances, the model has enabled a high and equal standard of living, high and gender-equal levels of employment, and extensive investments in education and research. The aim is a healthy life with opportunities for development, for both the individual and society. ${ }^{9,10}$

Naturally, we are not alone in finding new welfare solutions but, nevertheless, the Nordic Model is often cited as a role model, a "super model" ${ }^{11}$ One eye-catching example is how the high level of employment among women contributes to both gender equality and a high standard of living. The security provided by the social safety net is also said to promote innovative power in the Nordic region. People dare to and can think in new ways, because their entire existence is not at stake. Free education lays the foundation for a high and broad level of expertise, and a world-leading focus on research enables us to live in modern and high-tech communities up here in the north. ${ }^{12}$

It was committed people who formed associations and developed democracy. In small societies with many associations, like those in 
the Nordic region, flat hierarchies could be built up, and the communal construction of the welfare society required openness, transparency and freedom to express opinions verbally and in writing. The transparency is the fundamental explanation for the low level of corruption. The openness has generated trust in other people, in politicians and in the legal system - a trust that is unique in the world. ${ }^{13}$

Although each Nordic country has gone, and continues to go, its own way - for example, three countries are EU members and the others are not, three countries are members of NATO and the others are not - there is an unwavering desire to work together. Here too, the popular movements were first off the mark, when the Nordic Association was formed at the start of the last century. After two world wars, the feeling of closeness and interdependence was strengthened, and formal co-operation began between governments and parliamentarians. Quickly, and long before the European collaboration, this gave the Nordic region a passport union, a common labour market, and coordinated solutions for social security.

We have not just built welfare in collaboration with each other, but also with others. How could small countries like ours otherwise exist and survive? We have always been, and always will be, dependent on each other's knowledge, goods and friendship.

We have long experience of collaborating to improve conditions, and of building a societal model that offers people a dignified and meaningful life with opportunities for development. We believe we have something to offer those who are also looking for solutions to the challenges ahead. This concerns everything from ideas, knowledge, and sharing of experiences, to innovative and sustainable solutions.

It has been said that we have come this far by being Nordic, so that, quite simply, is what we should continue to be - Nordic.

Naturally, our location on the planet and our history have provided us with our own and unique perspective. We perhaps do the same things as many others, but we do them our way, from a joint platform that defines our particular strengths:

- Openness and a belief in everyone's right to express their opinions.

- Trust in each other and also, because of proximity to power, trust in leaders in society.

- Compassion, tolerance, and conviction about the equal value of all people.

- Sustainable management of the environment and development of natural resources.

- New ways of thinking, with focus on creativity and innovations. 


\section{Use of the strategy}

Now that the aim of international branding of the Nordic region is clear, and the common values are identified, what remains is to prioritise what we primarily want to communicate, and where. This selection of priorities will not preclude other activities, but coordinated messages are stronger, which is necessary if positions are to be strengthened in today's message society.

The following are the current priorities, identified as branding areas by a broad spectrum of public and private players.

\subsection{Strategic areas for branding}

Strategic areas for branding within the time horizon of this strategy have been formulated on the basis of the overall political priorities of the Nordic co-operation - currently Sustainable Nordic Welfare and Green Growth - and the current political priorities of the individual countries. The selection is also influenced by initiatives regarding major projects in the culture area. The prioritisations will highlight areas that, from a Nordic perspective, can be developed in dialogue with the outside world, and they are based on two main considerations:

1 What the Nordic region can offer the outside world.

2 How relationships in other parts of the world can benefit the Nordic region.

Certain activities may only concern one or possibly more of the selected branding areas, while others may concern all of them.

\subsubsection{The Nordic Model}

Since the financial crisis in 2008, the outside world's interest in the Nordic Model has grown considerably. Briefly, the model involves using healthy state finances to enable a high and equal standard of living, distributing welfare and social protection in the name of equality, a labour market that is greatly regulated by collective agreements between labour market parties, and extensive investments in education and research.

The Nordic Model shows that gender equality leads to a high level of employment and produces working conditions that offer a good life at the end of the working day. The model also shows that an open and trusting society promotes innovative and creative thinking. The effectiveness of the Nordic Model lies in its proven ability to proactively reform itself to meet prevailing challenges. Pragmatism is another characteristic. 
The model is also based on actively relating to the world around us, and on a conviction that stability promotes trade, greater knowledge, mutual cultural understanding, and sustainable development. ${ }^{14,15}$

The Nordic Model develops in harmony with the world around us, and we believe that in an international perspective it can offer solutions to future challenges. Consequently, we want to build a brand of the Nordic Model and increase awareness of it, in parts and as a whole.

\subsubsection{The Nordic region as a knowledge society}

A high level of knowledge is an important explanation for the international position of the Nordic region. Free access to education allows the individual to develop, which benefits the competitiveness of business. Researchers and others in the knowledge sector are given great opportunities to develop in their specialist areas, since they are able to work in all Nordic countries and not just one. In many areas, research in the Nordic region is of high international quality, such as within new technology and infrastructure, health, environment and climate, not least the conditions in the Arctic.

The Nordic knowledge society can both provide keys to basic education for more people in the world and also be part of world-leading research.

We are dependent on the world around us in order to continually raise the level of research. By drawing attention to researchers' opportunities for development, we will attract more people who want to achieve things in an international research environment in the Nordic region.

\subsubsection{Nordic creativity and innovation}

The high rankings of the Nordic countries in international surveys of creativity and innovative power stem from the Nordic Model. In addition to investments in education and research, a social security system allows people to take risks, to dare to fail. The business community is largely specialised and high-tech, and there are great opportunities to develop and be developed as a part of industry.

Striving for environmentally, economically and socially sustainable development requires international collaboration. Some areas of strength that the Nordic region can contribute are green/clean technology, bioeconomy, digital technology, entrepreneurship, and health and welfare.
14 Does the Nordic Mode Need to Change? ETLA Research Institute of the Finnish Economy \& Nordic Council of Ministers (2014).

15 The Nordic Way, World Economic Forum, Swedish Institute (2012). 
The place of culture throughout the population, and its close links to Nordic values, has helped develop the industries that are often called creative, such as literature, film, music, design, architecture, cuisine, and computer games. In one perspective, culture is an instrument for growth, as shown by many years of Nordic success in the area.

By working on many fronts - branding, looking for collaboration opportunities, and conducting business - we want to promote innovative and creative solutions based on sustainable approaches.

\subsubsection{Nordic culture and nature}

We look at the world from a Nordic horizon. This gives us our perspective. A largely common culture is the basis of the Nordic co-operation and of "the Nordic Region" as a concept.

The values of openness, popular participation, and proximity to power are building blocks of the Nordic Model. The model gives the Nordic cultural expressions a special image, which currently and increasingly is fascinating the outside world, and is reflected in concepts like Nordic Noir, Nordic Design, New Nordic Food, and The Nordic Music Wonder.

The historically strong bond between the Nordic people and nature, and the attitude to the environment that this has generated, permeates culture but also the relationship to nature itself. In an interplay between culture, nature, and social responsibility, we strive to successfully manage our heritage. The common responsibility for natural and human resources permeates decision-making in both business and politics.

There is plenty of space in the Nordic region. There are vast plains, high mountains, dense forests, and large oceans, and people are free to spend a lot of their recreational time there, because of a labour market model that allows time for both work and leisure. A sustainable approach with people at the centre influences politics at a general level.

Culture and the natural environment are central in branding the Nordic region. Both tell the story of the people who live here, and those who move here are welcome to become part of what safeguards our place on the Earth. We offer the entire palette of cultural and natural experiences to tourists who come here, and hope that they return home as ambassadors for what we are and what we stand for. 


\subsubsection{Other activities}

Note that selecting a few major initiatives does not preclude other activities in the countries, in the sectors, or within the Nordic cooperation. As expressed earlier, the strategy will not limit the work of the individual countries or players in branding their particular strengths. The aim of a joint Nordic branding strategy is to supplement and strengthen each country's individual brand by also helping to present a clearer and more consistent image of the common region.

\subsection{Prioritised geographical areas}

Branding initiatives should focus on areas where the Nordic countries have clear global competitive advantages and where there is an added value in presenting themselves as Nordic.

Sector-specific players coordinate their choices of geographical areas on the basis of the outside world's interest for the area in question.

The following geographical focus areas have been identified on the basis of an extensive anchoring process outside the Nordic region, in the Nordic countries and in the Nordic co-operation organisations.

\subsubsection{Regional neighbours}

Already established collaborations are worth protecting. The Nordic co-operation has enjoyed many years of collaboration with neighbouring countries, particularly in the Baltic Sea area and with other EU countries. Many Nordic players have close relations in these areas, where there is a growing interest in Nordic positions of strength. Already existing relations with the USA and Canada are worth intensifying.

\subsubsection{Remote markets}

The greater the distance from the Nordic region, the less is known about each Nordic country. This makes the Nordic region a more relevant concept, and joint Nordic initiatives will produce greater benefit.

Parts of the BRIC countries (Brazil, Russia, India and China) and South Africa are particularly identified; these are exerting increasing influence on global development and are becoming important targets for longdistance Nordic initiatives. 


\section{Target groups}

Branding of countries and regions involves many parties; target groups are broad and general, so no specific target groups are identified here. Every activity is unique, and must carefully identify its own target group or groups. Knowledge of the tangible needs of the target groups is necessary in order to be interesting and relevant. Consequently, ahead of every branding project, a thorough analysis will be carried out to define relevant target groups. ${ }^{16}$ 


\section{Objectives}

Because this strategy involves a broad spectrum of Nordic players and partners with ambitions in different fields, the objectives are described in general terms without tangible outcome goals. However, each international branding initiative must identify its own specific outcome goals, and monitor and evaluate them. The Nordic Council of Ministers' Secretariat will be responsible for a comprehensive evaluation and analysis of the results, which will help improve the ability to carry out international branding activities.

The aim and the long-term objective of the strategy, i.e. that the competitiveness and international influence of the Nordic region and the Nordic countries will be strengthened through coordinated branding activities in a joint initiative, will be attained through the following:

- The Nordic Council of Ministers will assume responsibility for coordinating and systematising initiatives that reflect the strategic focus described in this document.

- The Nordic Council of Ministers' Secretariat will develop a communication platform in line with this strategy, and practical tools that will inspire, help and support the branding activities of all stakeholders.

- The Nordic Council of Ministers will allocate a central budget to enable development of more visible and more effective branding activities.

- Players in the Nordic co-operation and in the Nordic countries will initiate activities and act on the basis of the strategy.

This will result in the following:

- Greater visibility, knowledge about and interest in the Nordic region and countries among the prioritised target groups and in the prioritised geographical areas.

- The joint activities carried out will have great impact.

- The joint activities carried out will have proven cost-effectiveness and coordination effects.

At the end of the strategy period, the effect will be evaluated through an overall assessment of the outcome goals attained in each individual project. The results will provide a guide for the tangible goals that will be set when the strategy is updated in 2018. 


\section{Success criteria for projects and activities}

\section{Market research to assess timing and to identify correct target groups}

The benefit is greatest when the appointed partner in the selected target location is known to have an interest in and a need for exchange. By identifying and understanding the needs in the outside world, the right prioritisations can be made at the right time.

\section{Use local partners}

Branding should preferably be carried out in collaboration with a local partner, who will help to communicate the message. Experience shows that credibility and impact are greater when the branding is also carried out via another party. An example is the Kennedy Center, which was crucial to the success of Nordic Cool 2013.

\section{Think bigger and across borders}

All countries and regions are active in many arenas and in all channels. Background noise is immense when it comes to information. Coordinated and value-adding activities with wellconsidered messages require more work, but have greater impact and generate more synergies.

\section{Long-term approach, planning and anchoring}

Individual and temporary initiatives lead nowhere. They are a waste of money. Long-term planning of more and varied, but coordinated, initiatives bring results. Regard branding as an opportunity in all operational planning, and start collaboration in good time. Good coordination within the group of players is vital.

\section{Evaluate and stay on course}

Surveys and evaluations raise the level of expertise and pave the way for constant improvements. Sharing experiences at Nordic level produces greater knowledge than at individual national level. By building further on the relationships that every activity generates, long-term and valuable relationships are created. 


\section{Budget}

Starting in 2016, a central budget item will be set up for the coordinating activities involved in identifying, preparing and coordinating major international branding initiatives. Relevant public and private sectors and players will then contribute to the implementation of the activities.

The Nordic Council of Ministers' Secretariat will be responsible for providing professional expertise in the branding area, and for coordinating and producing joint communicative products and practical tools. An advisory group will be set up with the task of assuring the quality of the selected activities, and ensuring that they are carried out in line with the branding strategy. The group will comprise professional expert representatives from each Nordic country. 


\section{Schedule and implementation}

The strategy applies from 2015 until 2018. Its activity plan and other practical tools will be continually updated, at least once a year. A longterm approach and continuity are important, but an annual update is needed to capitalise on new opportunities and to gradually convert strategic prioritisations into tangible activities on the basis of results and experiences.

The year of implementation for the strategy and its tools will be 2015 . In an introductory phase, the strategy will be translated into the Nordic languages and English, and then formally distributed to the players that contributed during the preparation process, including the pilot study.

In this phase, the work will begin on developing and systematising tools and other material aimed at supporting the work on international branding of the Nordic region. In phase two, the tools will be made available on www.norden.org and will be implemented in the network. The Nordic Council of Ministers' Secretariat will be responsible for implementation within the Nordic co-operation, and will help with implementation in the countries and with other players.

\subsection{Implementation plan}

- 27th October 2014: The Nordic Ministers for Co-operation adopt a strategy for international branding of the Nordic region.

- November-December 2014: Strategy translated into the Nordic languages and English.

- January 2015: Strategy distributed to all relevant players.

- 2014-2015: Production of materials and tools (communication platform, web, publications, statistics, templates and other tools).

- Mid-2015: Workshops arranged with the aim of implementing the strategy and tools.

- Identify major initiatives for 2016-2018 (note that Denmark, which holds the presidency in 2015 , has already made some prioritisations). 


\section{Practical tools}

The Nordic Council of Ministers' Secretariat will have a facilitating and coordinating role in the joint strategy work. This will involve responsibility for assuring the quality of the initiatives, and providing and coordinating practical tools. The aim is to develop tools that will inspire, help and facilitate the branding work for all stakeholders. The tools can be used as a package or combined with other messages and tools.

\section{The following tools will be made available:}

\section{Communication platform}

The aim of a communication platform in line with the branding strategy is to help players communicate and visualise the Nordic region internationally, and to ensure streamlined communication. The platform will contain:

- A general and brief description of Nordic positions of strength, cf. the strategy.

- Template for the communication process.

- A check list for evaluating future project initiatives.

- Guidelines for outcome goals.

- Guidelines for identifying target groups.

- Use of the Nordic Story.

\section{Activity plan for joint initiatives}

Review of branding activities and other activities with branding potential; for example, review and possibly coordinate Nordic ministerial delegations, with the aim of efficiently coordinating trips to promote branding.

\section{Template for larger branding projects}

A well-defined template that can be immediately activated in conjunction with decisions to implement major international branding projects. This will build on results from one of the projects during the Danish presidency 2015 and on experiences from the work relating to Nordic Cool 2013.

Current statistics and information about the Nordic region and countries A tool will be developed for importing and showing updated factual material and statistics. The Nordic countries are ranked highly, for example in international surveys, which will also be made accessible. 
Overview and updated information about Nordic areas of strength and success stories - Nordic Talking Points

An overview and short presentation of Nordic core values and positions of strength will be developed to support the communication work, categorised according to the strategic branding areas.

Knowledge bank in the form of experiences from implemented activities With the aim of sharing experiences, analyses and measurements carried out in connection with branding-related projects. 


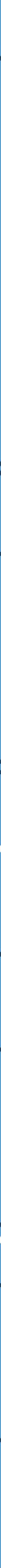




\section{norden}

Nordic Council of Ministers

Ved Stranden 18

DK-1061 Copenhagen K

www.norden.org

\section{Strategy for International Branding of the Nordic Region}

The Nordic region is appealing. For some time, characteristically Nordic cuisine, design, films, music and literature have been bringing the Nordic region international recognition. The successes, which come from all the Nordic countries, often share a distinctly Nordic element - a Nordic trademark.

However, the Nordic region first started to distinguish itself internationally in the aftermath of the financial crisis. The Nordic governance and welfare model once again showed it was capable of renewing itself. Countries all over the world then began to discuss whether our model could serve as a possible buffering and stabilising factor in an increasingly uncertain global economy.

We in the Nordic region are also facing a number of serious challenges. We are far from perfect, and it is perhaps this imperfection that makes us fascinating. 